\title{
Climatological aspects of South Pacific tropical cyclones, based on analysis of the RSMC-Nadi (Fiji) regional archive
}

\author{
James P. Terry ${ }^{1, *}$, Gennady Gienko ${ }^{2}$ \\ ${ }^{1}$ Department of Geography, National University of Singapore, AS2, 1 Arts Link, Kent Ridge, Singapore 117570 \\ ${ }^{2}$ Department of Geomatics, School of Engineering, University of Alaska Anchorage, 3211 Providence Drive, Anchorage, \\ Alaska 99508-4514, USA
}

\begin{abstract}
This study analyses the regional cyclone archive for the tropical South Pacific $\left(160^{\circ} \mathrm{E}-120^{\circ} \mathrm{W}, 0^{\circ}-25^{\circ} \mathrm{S}\right)$ maintained by the designated Regional Specialized Meteorological Centre located at Nadi in the Fiji Islands. The historical cyclone record was examined over 4 decades from the 1969-1970 cyclone season to the 2007-2008 season. Cyclogenesis origins, minimum pressures, durations and track parameters (azimuth and length) of 291 individual storms were investigated. Temporal variability in separate cyclone parameters was highly variable but not necessarily matching on an interannual basis. Anomalous periods of cyclone behaviour can be detected in 1976, 1981, 1983, 1991, 1998, 2001-2002 and 2003. Strong and significant inter-relationships are indicated between storm longevity, track length and minimum sea-level pressure (MSLP) attained, and also between seasonally averaged measures of latitude of cyclone origin and the strength of the Southern Oscillation Index and Multivariate ENSO Index. Yet no overall long-term linear trends were detected in the data, with the exception of MSLP which showed a spurious decreasing trend - a problem already highlighted in other cyclone archives. These findings suggest that the South Pacific cyclone basin and the islands therein will continue to experience strong but irregular interannual fluctuations in cyclone and track characteristics. Such anomalies will remain a much more dominant feature of temporal patterns than possibly evolving changes in long-term average cyclone activity resulting from climate change.
\end{abstract}

KEY WORDS: Tropical cyclones $\cdot$ South Pacific $\cdot$ Historical record $\cdot$ RSMC-Nadi

\section{INTRODUCTION}

In terms of both numbers of people affected and overall financial costs, cyclones remain the most destructive natural hazard in the tropical South Pacific. They pose an annual threat to the livelihoods of populations inhabiting the scattered nations of Oceania and regularly affect the sustainability of their small-island economies. In January 2003 for example, floods caused by Cyclone Ami killed 17 people and wiped out food crops across northern areas of Vanua Levu Island in Fiji (Terry et al. 2004); in January 1 yr later Cyclone Heta wrought devastation on the tiny nation of Niue, costing over NZ\$35 million (Barnett \& Ellemor 2007), equivalent to approximately double the national GDP. Fortunately, not all storm events cause such severe impacts in the South Pacific, but these examples nevertheless underscore the need to maintain current scientific focus on understanding tropical cyclone behaviour. Furthermore, there is mounting evidence to indicate that some cyclone characteristics (e.g. intensity, rainfall) in affected ocean basins are likely to change as sea surface temperatures rise in tandem with enhanced greenhouse conditions (e.g. Walsh \& Ryan 2000, Emanuel 2004, 2005, Knutson \& Tuleya 2008), while recent work suggests an increasing occur- 
rence of the most intense storms ( $\leq 945 \mathrm{hPa})$ across the wider Southern Hemisphere (Kuleshov et al. 2008).

Part of the process of investigating the (possibly) evolving nature of cyclone behaviour involves an examination of records of past events (e.g. Webster et al. 2005). This is not without difficulties because meaningful interpretation of any finding must be cautious of bias introduced by the improving reliability of historical records and the continual advancements made in cyclone observation technology (Klotzbach 2006, Landsea et al. 2006). Yet as long as the deficiencies in historical records are recognised, then there is no need to ignore outright the information that such data sets are able to provide. Historical records will therefore remain valuable for comparison with future observations, in order to assess any change in cyclone activity (Murnane 2004).

In the present study, we are among the first to examine the record of cyclones in the tropical South Pacific that is archived by the Regional Specialized Meteorological Service (RSMC) operated by the Fiji Meteorological Service (FMS). The historical record maintained by the FMS includes data on all storms from 1970 to 2008. Utilising this archive, GIS tools and simple statistical methods were used to examine fundamental cyclone characteristics over the last 4 decades of observations. The principal aim of the present study was to present information derived from the FMS record on cyclone origins, durations, intensities and various other cyclone track parameters, and then to determine the strength of any relationships between these cyclone metrics. Whether or not credible trends and temporal variability in these parameters can be identified was also explored. The results will thus provide a set of independent observations that can be compared with findings based on alternative archives of cyclones in the study region, of which several exist.

\section{STUDY AREA}

The FMS is the authority designated by the World Meteorological Organization (WMO) to operate the South Pacific RSMC, based at Nadi in the Fiji Islands (RSMC-Nadi). RSMC-Nadi is one of only 6 RSMCs worldwide, and was designated in 1995. Its area of responsibility extends from the equator to latitude $25^{\circ} \mathrm{S}$ and from longitude $160^{\circ} \mathrm{E}$ to $120^{\circ} \mathrm{W}$ (Fig. 1). For the purposes of the present study, this area will be referred to as the tropical South Pacific (TSP). Within this region lie thousands of islands belonging to over 15 developing small-island nations and territories. Although many of these states operate their own national meteorological services, it is the task of the RSMC-Nadi to detect, name and monitor all tropical cyclones originating in this operational region. The adjacent area to the west of the TSP is called the Coral Sea; cyclones originating in this area are named by the Tropical Cyclone

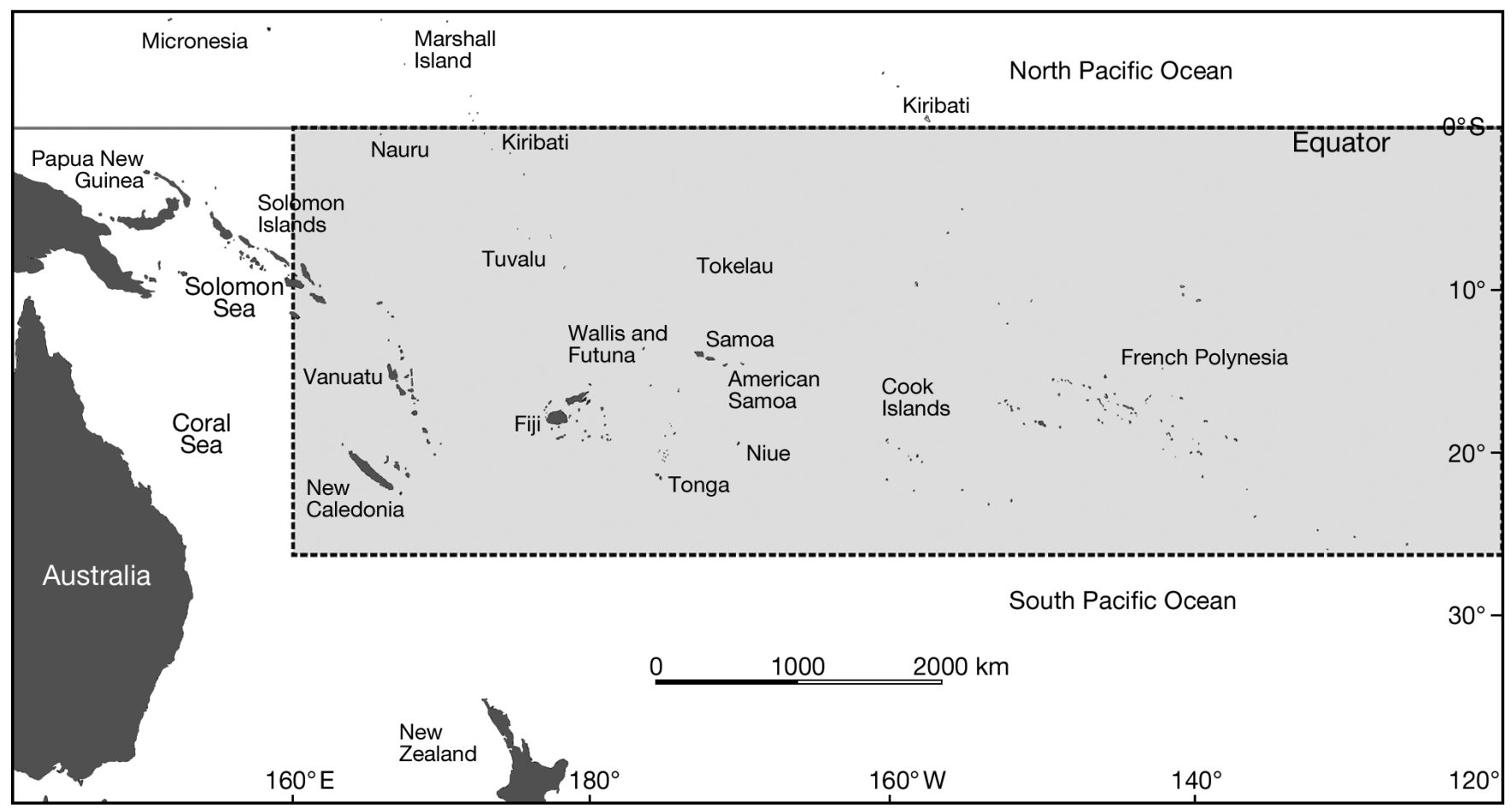

Fig. 1. Area of responsibility of the RSMC-Nadi in Fiji (grey box), and the island nations and territories across the tropical South Pacific 
Warning Centre in Brisbane, Australia (TCWC-Brisbane), but are included in the TSP data set if they move east of $160^{\circ} \mathrm{E}$. Similarly, the TSP data set includes information on storms moving into subtropical waters south of $25^{\circ} \mathrm{S}$, which fall under the responsibility of the TCWC in Wellington, New Zealand (TCWC-Wellington). The complete TSP data set is archived by the Climate Services Division of the FMS.

\section{METHODOLOGY}

\subsection{Source data}

Observations of cyclones in the tropical South Pacific have been collected for several decades by the FMS, and prior to Fiji independence in 1970 by the New Zealand Meteorological Service operating out of Nadi. Data collected during the satellite era since the late 1960s have a higher degree of accuracy and reliability than earlier records, so the present study utilised only the TSP data from 1969 onwards, when satellite observations were first introduced for monitoring in the
South Pacific. The current RSMC-Nadi best track database for the TSP is a set of records containing the cyclone name, time stamp, position (latitude, longitude), sea-level pressure and wind speed recorded at fixed time intervals. While early tracking techniques used $12 \mathrm{~h}$ intervals to trace cyclone positions, observations since 1985 have used 6 hourly fixes to obtain more precise positioning of storm tracks. While the essential information from 1969 until 2008 is generally congruent (name, date, time, position, sea-level pressure and wind speed), various different arrangements to store data have been used over time; Table 1 illustrates some examples. Therefore, a decision was made to reformat all source data into a uniform style. This created a single database containing data on 341 tropical storms with over 8400 individual track position records, which enabled batch processing using both universal programming tools and statistical analysis packages.

Data pre-processing highlighted several problems related to errors in the source data. Two main types of errors occurred, namely wrong location and missing data. In response, several steps and iterations were

Table 1. Storm best track data formats in the RSMC-Nadi record: examples of header and first 2 data rows. TIME and HHHH: time for position fix; PPP and PRES: central pressure (hPa); MAX and W(KT): maximum sustained windspeed (knots); TC: tropical cyclone; Category: TC category assigned by meteorologist on duty. Original columns containing no relevant data have been omitted. Some TC names in records contain season (year) (example: WALLY_1979), some do not. Some records contain numerical values with information about year/season in implicit form (example: CORA_BT_19082). Date, time and position formats are not consistent and change through databases. The RSMC-Nadi databases contain manually inserted records such as 'Tropical Depression (TD) Phase' or 'Named by RSMC Nadi', so filtering non-digital data is needed

\begin{tabular}{|c|c|c|c|c|c|c|c|c|c|}
\hline NAME & DATE & TIME & POSITION & MAX & PPP & & & & \\
\hline $\mathrm{ADA}$ & 03-JAN-1970 & 00:00Z & $\left.16.0^{\circ} \mathrm{S}, 165.0^{\circ} \mathrm{E}\right)$ & 30 & 997 & & & & \\
\hline $\mathrm{ADA}$ & 03-JAN-1970 & $12: 00 \mathrm{Z}$ & $\left(16.2^{\circ} \mathrm{S}, 163.6^{\circ} \mathrm{E}\right)$ & 30 & 997 & & & & \\
\hline NAME & DATE & TIME & LAT & LONG & PPP & MAX & & & \\
\hline WALLY_1979 & 19800402 & 0000 & 14.3 & -179.5 & 997.0 & 30 & & & \\
\hline WALLY_1979 & 19800402 & 1200 & 15.0 & 179.5 & 997.0 & 30 & & & \\
\hline NAME & DATE & TIME & LAT & LONG & PPP & MAX & & & \\
\hline VIOLET_19043 & 19950303 & 0000 & 15.5 & 151.0 & 997.0 & 30 & & & \\
\hline VIOLET_19043 & 19950303 & 0600 & 15.8 & 152.0 & 995.0 & 35 & & & \\
\hline NAME & DATE & TIME & LAT & LONG & PPP & MAX & & & \\
\hline CORA_BT_19082 & 19981221 & 0000 & 14.0 & -173.5 & 1002.0 & 25 & & & \\
\hline CORA_BT_19082 & 19981221 & 0600 & 14.3 & -173.8 & 1002.0 & 25 & & & \\
\hline \multicolumn{10}{|c|}{ 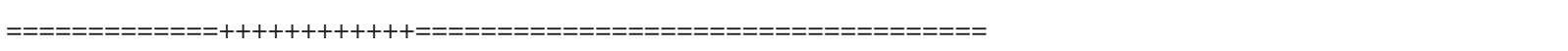 } \\
\hline NAME & YYYY & $\mathrm{MM}$ & DD & $\mathrm{HHHH}$ & LAT & LONG & PRES & $\mathrm{W}(\mathrm{KT})$ & Category \\
\hline \multirow{2}{*}{\multicolumn{10}{|c|}{$\begin{array}{l}=========================++++++++++++======================= \\
\text { Tropical Depression (TD) Phase }\end{array}$}} \\
\hline & & & & & & & & & \\
\hline TAM & 2006 & 01 & 11 & 1200 & 14.0 & 179.5 & 997 & 30 & \\
\hline TAM & 2006 & 01 & 11 & 1800 & 14.2 & -179.6 & 996 & 30 & \\
\hline \multicolumn{10}{|c|}{ TC Phase } \\
\hline \multicolumn{10}{|c|}{ Named by RSMC Nadi } \\
\hline TAM & 2006 & 01 & 12 & 0000 & 14.5 & -178.5 & 995 & 35 & \\
\hline TAM & 2006 & 01 & 12 & 0600 & 14.8 & -177.4 & 990 & 40 & \\
\hline
\end{tabular}


developed for data checking and correction. Consistency of date/time stamps and geographic coordinates were checked automatically by programming appropriate scripts. Random errors in geographic locations of tracks are harder to identify using automated approaches, so visual inspection of cyclone plots was used to spot suspicious tracks and particular fixes. These were checked against an alternative record maintained by TCWC-Wellington. The most challenging task involved processing cyclone tracks registered by 2 authorities at the same time (e.g. RSMC-Nadi and TCWC-Wellington). Such situations occured when cyclones originated within one area of responsibility but then travelled into an adjacent area, e.g. by crossing $160^{\circ} \mathrm{E}$ or $25^{\circ} \mathrm{S}$. To complete the whole tracks for such cyclones, records from 2 complementary data sets were cross-checked and then merged.

\subsection{Defining cyclone tracks within the study area}

Two criteria were used for the selection of storm tracks for analysis from the comprehensive RSMCNadi data set: (1) entry into the TSP study area and (2) attainment of cyclone intensity. The first criterion was easily determined using GIS tools to filter out those storms that formed in the Coral or Solomon Seas but did not cross $160^{\circ}$ E. Fig. 2 illustrates the combinations of possible track positions relative to the study area, showing those that were selected or filtered. For the second criterion, phases of tropical cyclone intensity are normally defined by sustained wind speed at each recorded fix along a cyclone track. While particulars of cyclone phases and corresponding intensity classifications vary for different ocean basins (see BoM 2009 for details), most approaches define the starting point of a
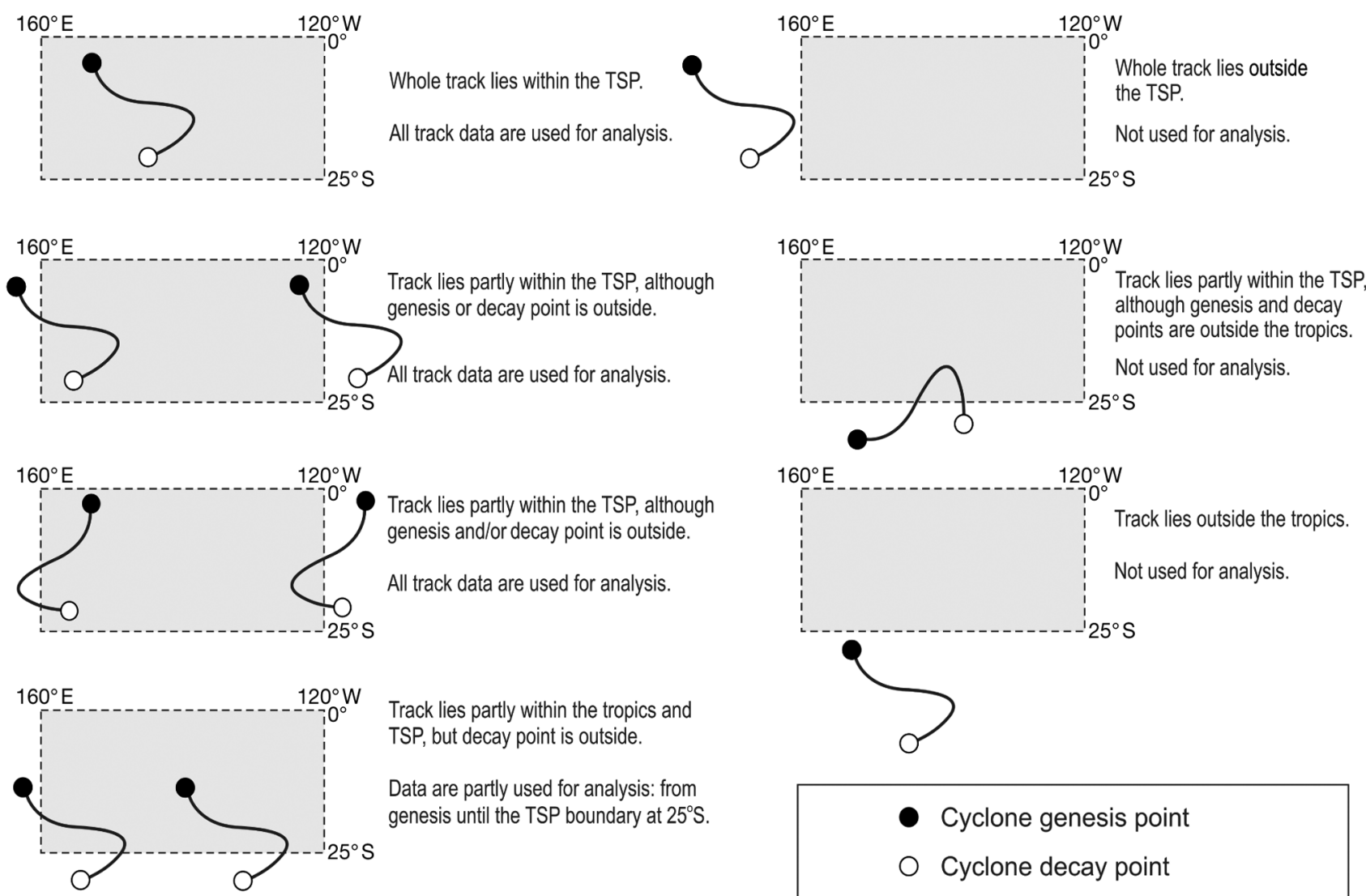

Track lies partly within the tropics and TSP, but decay point is outside.

Data are partly used for analysis: from genesis until the TSP boundary at $25^{\circ} \mathrm{S}$

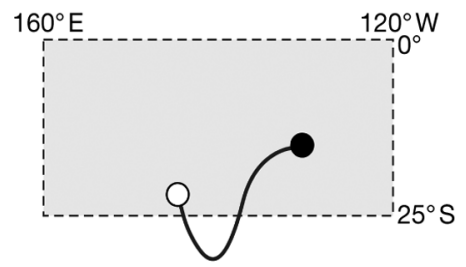

Track lies partly within the tropics and TSP; genesis and decay points are inside the TSP

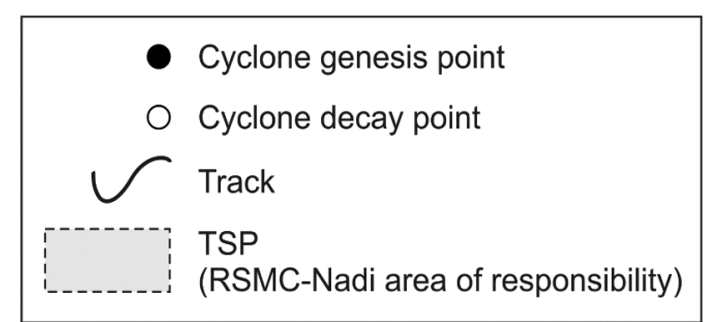

All track data are used for analysis.

Fig. 2. Variations of cyclone track possibilities that are either entirely within, or that cross, the tropical South Pacific (TSP) study area, showing tracks used in the present study (left) and those filtered out (right) 
tropical cyclone (TC phase) when the sustained wind speed reaches 34 knots (Terry 2007).

For the RSMC-Nadi data set, sustained wind speed represents $10 \mathrm{~min}$ averages and is recorded in $5 \mathrm{knot}$ increments. Thus 35 knots (the closest value to 34 knots) was chosen as the threshold to identify the genesis for each cyclone in consideration. At lower wind speeds, a migratory storm is termed a tropical depression or tropical disturbance (TD). Sections of tracks in early or late depressional phases of a cyclone were therefore excluded from analysis. For 150 cyclones, the first recorded track position already had wind speeds $\geq 35$ knots, the common reason being that storms often have a rapid development stage and thus mature from their TD to TC phase in less than the $6 \mathrm{~h}$ interval used to record storm location. In these cases the cyclogenesis position is counted as the first available record.

By analogy with the start point, the decay point of tropical cyclones should be defined when the wind speed eases below 34 knots. In practice, we decided against using the mathematically closest recorded value (35 knots) as the threshold, as at this wind speed the storm is still in a cyclonic phase. Instead, for storms which decayed within the study area, the last reading of 30 knots was used to identify the end of the cyclone track. Surprisingly, records of 75 cyclones finished at wind speeds of 40 knots or more at the last registered position. This is either because individual storms decayed rapidly to the TD phase in $\leq 6 \mathrm{~h}$, or had moved into open waters away from populated islands, so the RSMC-Nadi forecasters ceased formal operational tracking. In these cases, the final registered fix of the cyclone was used to mark the end of the track.
For those storms that migrated beyond the southern boundary of the TSP area $\left(25^{\circ} \mathrm{S}\right)$ while maintaining wind speed above 35 knots, the final track position was identified as the first record immediately beyond $25^{\circ} \mathrm{S}$. In other words, data from the region beyond $25^{\circ} \mathrm{S}$ are excluded from analysis. There are several reasons why this decision was made. First, virtually all the islands of the developing South Pacific nations are located above $25^{\circ} \mathrm{S}$, and it is in the context of their vulnerability to cyclones that the present study was undertaken. Second, cyclones moving beyond $25^{\circ} \mathrm{S}$ are entering cooler, sub-tropical waters. Transition from a tropical to an extra-tropical cyclone (ETC) occurs when the strongest winds become associated with the development of a southerly wind flow pattern into a cyclone (rather than the central cyclone environment itself). Although many ETCs continue further poleward as intense systems, they increasingly take on characteristics of mid-latitude depressions (MLDs). Yet this transition between ETC- and MLD-type systems is not always easy to distinguish. Third, the area below $25^{\circ} \mathrm{S}$ falls under the responsibility of the TCWC-Wellington, which does not routinely use the same set of satellite information as the RSMC-Nadi to define best tracks or make observations of pressure and wind speed. Consequently, from the original 341 tropical storms recorded in the RSMC-Nadi archive between 1969 and 2008, 291 of these eventually satisfied our selection criteria of reaching cyclone intensity and passing through the TSP area (Fig. 3). For these cyclones, observations up to the $25^{\circ} \mathrm{S}$ boundary were then used for further analysis.

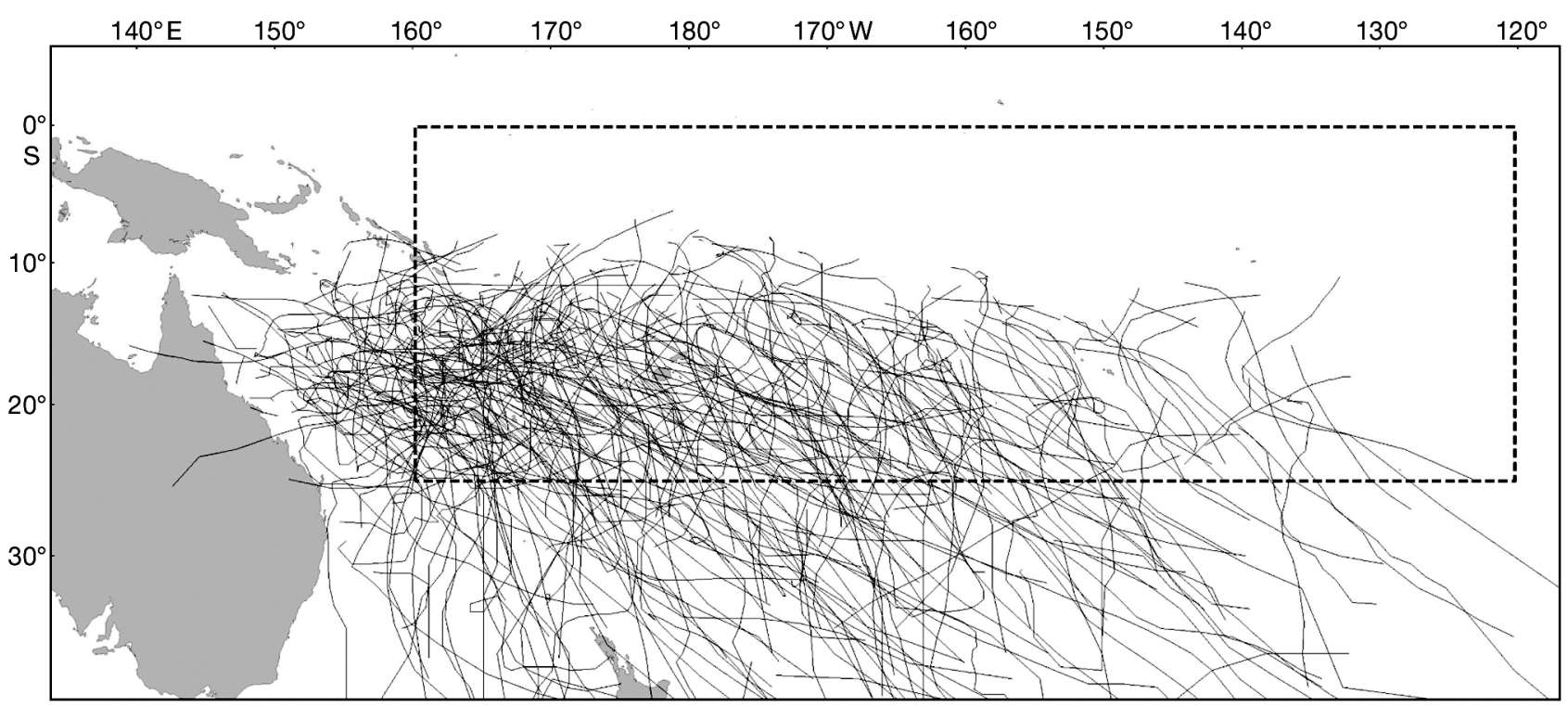

Fig. 3. Tracks of all 291 tropical storms that reached cyclone status and passed through the TSP study area (dashed box) between the 1969-1970 and 2007-2008 cyclone seasons. Only cyclone-intensity phases of the tracks are illustrated ( $\geq 35$ knots), i.e. early and late tropical depression phases are not shown 


\section{RESULTS AND DISCUSSION}

The traditional cyclone season in the tropical South Pacific extends for 6 mo from November to April, although some events have occurred outside these months. Our data set extends across 39 cyclone seasons, from 1969-1970 to 2007-2008. Within this time frame, a total of 291 cyclones passed through the TSP study area; the median frequency for the TSP is 7 events per season. Some additional cyclone statistics are presented in Table 2 .

\subsection{Variability and trends}

Fig. 4 illustrates all individual values of cyclone start latitude and longitude, minimum sea-level pressure (MSLP), duration, track length and track azimuth within the TSP from 1970 to 2008. Since intense cyclones generally last longer than weaker systems and are a greater threat in terms of destructive potential, there is a high degree of certainty that all of the most intense storms have been captured in the record (R. Prasad pers. comm.). From Fig. 4 it is immediately apparent that there is very large seasonal and interannual variability, a problem that has already been identified when attempting meaningful analysis of historical data sets (Walsh 2004). Central running averages of storm parameters were therefore also plotted, based on the seasonal frequency, i.e. 7 events. Running medians were used in preference to running means as they are more robust to the extreme values of some atypical events in the record, such as Cyclone Rewa in 19931994 which set unprecedented records for duration (23 d) and track length $(8427 \mathrm{~km})$, and Cyclone Zoe in late 2002 to early 2003, which plummeted to a record MSLP of $890 \mathrm{mb}$ (FMS 2003). Each of the measured cyclone parameters show periods of great deviation from average conditions. Of particular interest in this regard is that although some correspondence is noticeable between periods of either pronounced fluctuation or rela-

Table 2. Summary cyclone characteristics from the 1969-1970 to 2007-2008 seasons within the tropical South Pacific (to $\left.25^{\circ} \mathrm{S}\right)$, derived from the RSMC-Nadi best track database. MSLP: minimum sea-level pressure

\begin{tabular}{|lcc|}
\hline Parameter & Median & Range \\
\hline Seasonal frequency & 7 & $2-16$ \\
Start latitude $\left({ }^{\circ} \mathrm{S}\right)$ & 14.7 & $6.1-25.0$ \\
Start longitude $\left({ }^{\circ} \mathrm{E}\right)$ & 175.0 & $139.2-227.3$ \\
MSLP $(\mathrm{mb})$ & 975 & $890-996$ \\
Duration $(\mathrm{d})$ & 3.75 & $0.25-23.0$ \\
Track length $(\mathrm{km})$ & 1688 & $119-8472$ \\
Track azimuth $\left({ }^{\circ}\right)$ & 147.4 & $65.7-276.0$ \\
\hline
\end{tabular}

tive quiescence, there is neither a precise match in direction nor degree of variability through time. The following anomalous periods can be identified for different parameters in the TSP area. For cyclogenesis latitude, 1991-1992 and 1998 were unusual years of more northerly storm origins, whereas 2000-2001 experienced storm origins farther south than normal. Post-2001 appears as a phase of more steady averages. For cyclogenesis longitude, 1983 showed the largest deviation eastwards. Track azimuth experienced strong swings to the west of south in 1976 and 1981. Cyclone MSLPs were exceptionally low in both 1983 and 2003. Track lengths were notably longer than usual in 1985, but both track length and cyclone duration have been generally shorter than the long-term average since the early part of the current decade. Although it is beyond the scope of the present study to relate all these anomalous periods to any observed shifts in regional South Pacific climatic behaviour, the strength of interrelationships between measured cyclone parameters is considered in Section 4.2.

Linear trend lines have also been drawn through the data (Fig. 4). Perhaps the most important observation is that there is little evidence for long-term underlying change in the measured cyclone parameters. Cyclone MSLP is apparently the single exception, which seems to indicate a decreasing trend if plotted for the entire period of record $(r=-0.23, p<0.001)$, suggesting an estimated fall of approximately $20 \mathrm{mb}(2 \%)$ in average recorded minimum cyclone pressure over the last 4 decades. The question arises, however, of whether this apparent trend is reliable. The probable answer is no; the MSLP trend based on the original RSMC-Nadi data is in all likelihood a spurious trend. There are many potential reasons for this, but the 2 most significant influences are as follows.

(1) Owing to advances in available technology through time, there have been great strides made in cyclone detection and intensity analysis. This has undoubtedly introduced significant bias into the estimation of cyclone intensities and corresponding records of MSLP. A valuable review of such issues for northern Australia cyclone data, archived by the Australian Bureau of Meteorology (BoM), has recently been presented by Harper et al. (2008). They argue convincingly that the level of so-called instrumental bias, i.e. bias in intensity records due to improving tools (against an assumed constant climatology), is probably on the order of $35 \%$ underestimation of cyclone intensity in 1969 and $10 \%$ underestimation in 1980. Such effects declined in the BoM record after the regular use of geostationary meteorological satellite imagery in the early-mid 1980s. Similarly, to address problems of data inconsistencies, Kossin et al. (2007) performed a reanalysis of global satellite data to create 
a new homogenous archive. By examining hurricane (cyclone) intensity from the homogenised record, they reached the conclusion that some of the existing data sets may contain spurious or inflated trends. Thus an instrumental bias can reasonably be expected to also afflict the RSMCNadi archive data, perhaps continuing into the mid-1990s when the use of QuikSCAT orbiting satellite imagery became routine for wind retrievals (R. Prasad pers. comm.).

One way to establish the existence of bias is to compare cyclone MSLP data from RSMC-Nadi with the BoM and US Joint Typhoon Warning Center (JTWC) archives (NOAA 2010). Comparing RSMC-Nadi and BoM data is possible for 58 cyclones between 1970 and 2008; these cyclones tracked across $160^{\circ} \mathrm{E}$ and reached their minimum pressure somewhere near this longitudinal boundary while being monitored by both the FMS and the adjacent Tropical Cyclone Warning Centre (TCWC-Brisbane) at the same time. For these 58 storms, the average difference in MSLP between the RSMC-Nadi and BoM records is $\leq 1 \mathrm{mb}$. Similarly, comparing RSMCNadi and JTWC is possible for 38 cyclones between 2001 and 2008. For these 38 storms, the average difference in MSLP between the RSMCNadi and JTWC is 2 mb. Fig. 5 illustrates the strong relationship between these independent archives for individual cyclone MSLP data $(r=0.93$ and 0.96, p $\leq 0.001$ ), thereby implying that the problem of biased cyclone intensity data in both the BoM and the JTWC archives, as identified by

Fig. 4 (continued on next page). Measured values of various parameters for individual cyclones (black circles), long-term trends (horizontal dashed lines) and variability in running medians of 7 storms (solid black lines) from 1970 to 2008 in the tropical South Pacific. Black circles are spaced sequentially and equidistantly along the horizontal, so the time axis is non-linear. Vertical scales have been truncated for clarity, so on each graph several cyclones with extreme values are not shown
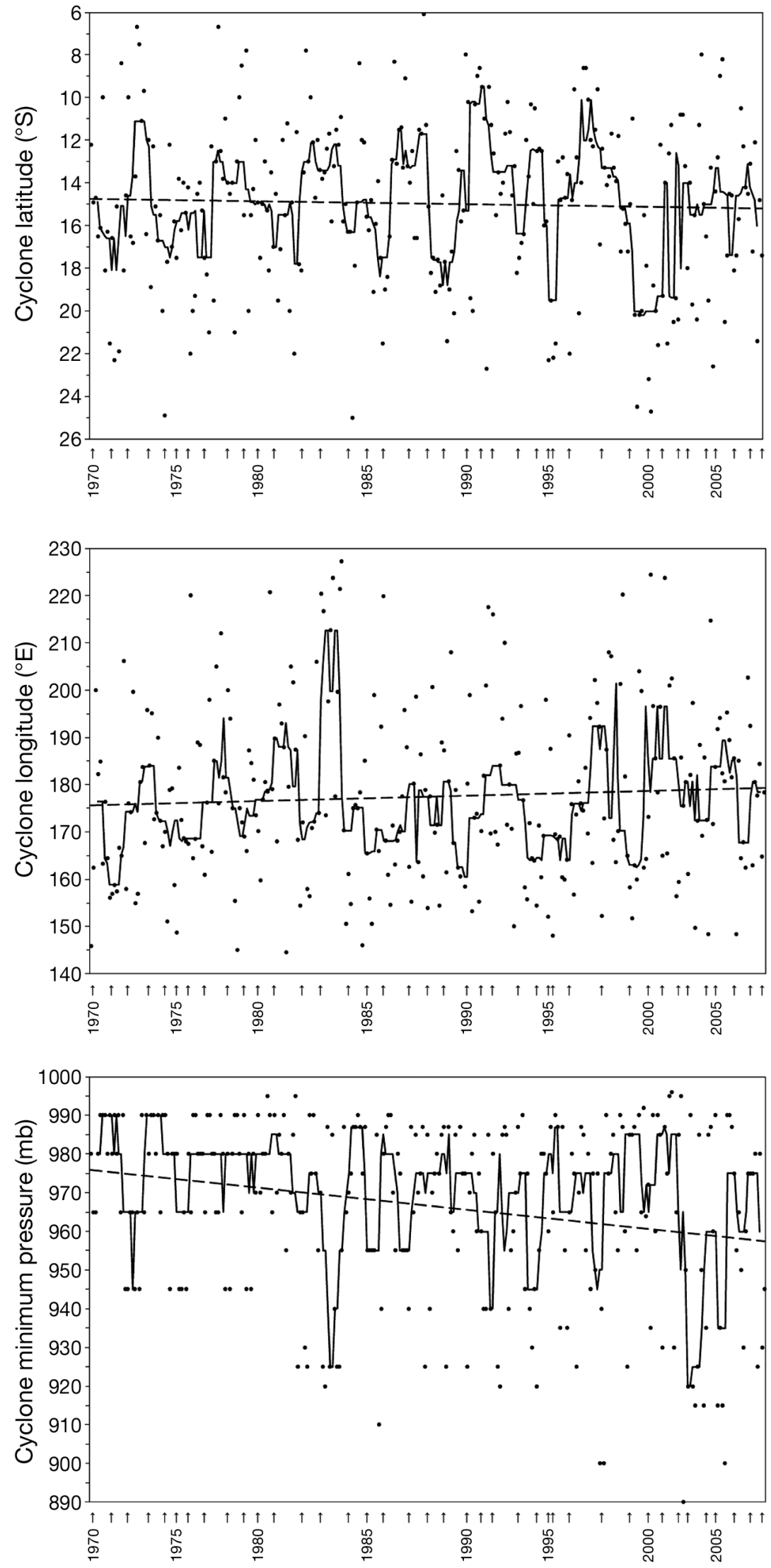

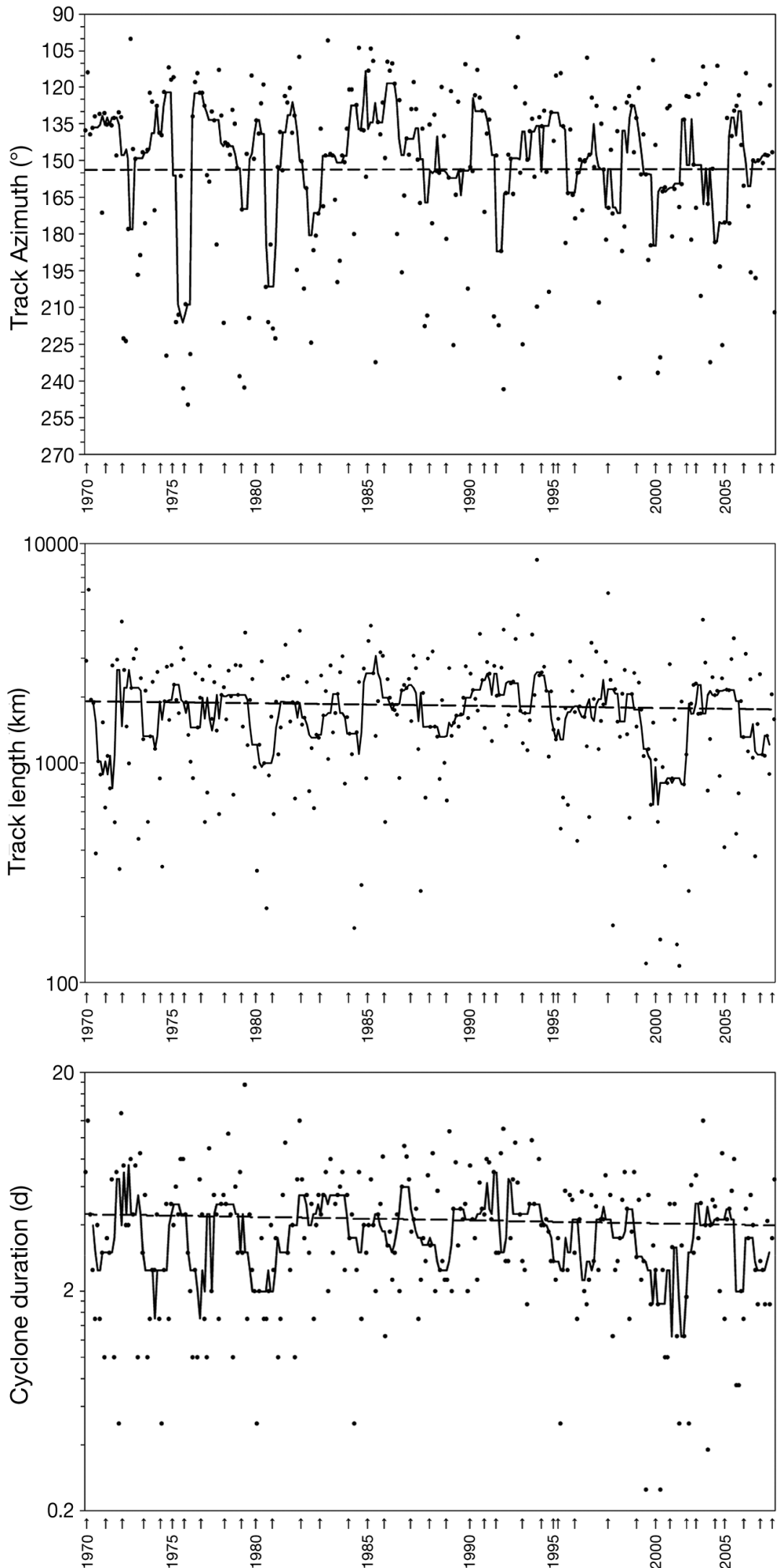

Fig. 4. (continued)
Harper et al. (2008) and Kossin et al. (2007), is also a significant feature of the RSMC-Nadi data set.

(2) The other major consideration is the effect of modifications to the actual wind-pressure relationships used by meteorological forecasters at RSMCNadi. Before the introduction of Dvorak's technique of cloud pattern recognition (Dvorak's 1975) it was difficult to estimate cyclone intensity. This was indeed the case for all cyclone basins without routine aircraft reconnaissance (J. A. Knaff pers. comm.). Consequently, in the earlier period of the RSMC-Nadi record (i.e. from 1969 to the late 1970s), cyclone intensity estimation was based on objective but non-standardised analysis of satellite signatures, similar to methodologies used in the Australian region (R. Krishna pers. comm.). The pioneering Dvorak (1975) method should therefore be regarded as a revolution for cyclone intensity work, especially because of its simplicity of application (Velden et al. 2006). The Dvorak technique was adopted by RSMC-Nadi sometime in the late 1970s, following the lead of the Australian TCWCs controlling the adjacent area west of $160^{\circ} \mathrm{E}$ (R. Prasad pers. comm.). Later, however, an updated methodology for enhanced infrared satellite images (Dvorak 1984) became preferred. This changeover in operational procedure for cyclone intensity estimation was critical because the wind-pressure conversions are quite different for intense tropical cyclones (Table 3), with the earlier Dvorak (1975) method likely being the more correct (Knaff \& Zehr 2007). Unfortunately, however, no documentation exists at RSMC-Nadi for fixing the time when the changeover occurred, although the swap was probably implemented after Dvorak himself personally visited the FMS in Fiji in the late 1980s to explain his techniques to regional forecasters (A. Waqaicelua pers. comm.). Thus, for cyclone MSLP it is necessary to examine any trend only for that part of the record that can be regarded as more reliably homogenous, i.e. 1990-present. For this much shorter subsection of the data set, no trend is detected in MSLP $(\mathrm{r}=-0.08)$. 


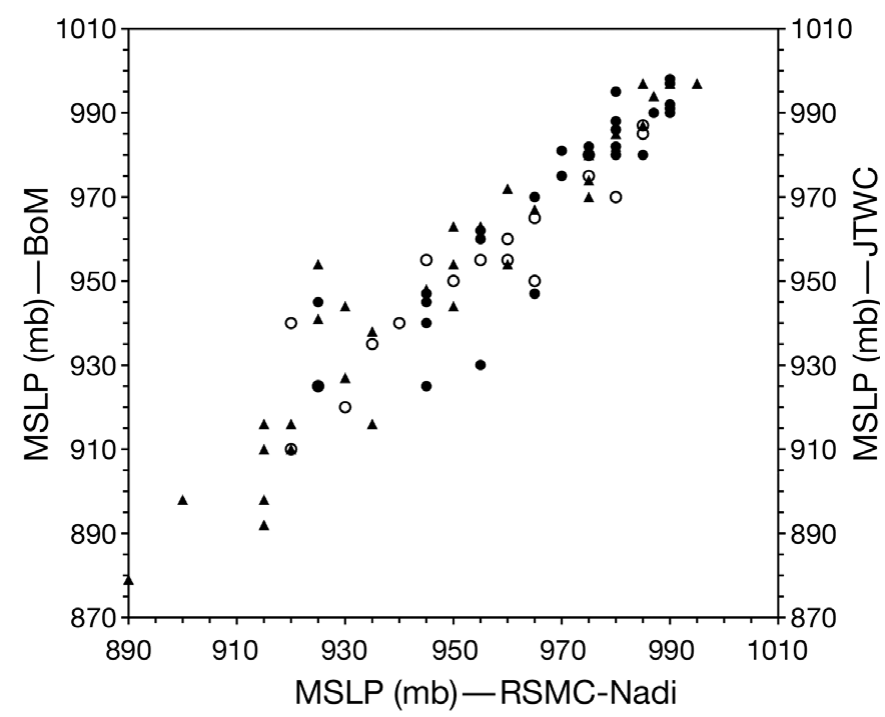

Fig. 5. Scatter plot of minimum sea level pressure (MSLP) data for tropical cyclones recorded in the RSMC-Nadi, Australian Bureau of Meteorology (BoM) and US Joint Typhoon Warning Center (JTWC) best track archives. The graph gives an impression of the similarity or dissimilarity of the maximum strength of individual cyclones recorded simultaneously by more than 1 centre. (•): RSMC-Nadi vs. BoM data (19701989, 33 storms); (O): RSMC-Nadi vs. BoM data (1990-2008, 25 storms); (ム): RSMC-Nadi vs. JTWC data (2001-2008, 38 storms). BoM and JTWC data are from NOAA (2010)

Table 3. Dvorak current intensity (CI) number for tropical cyclones, equivalent 1 and 10-minute sustained winds and comparison minimum central pressure given by Dvorak's (1975, 1984) methodologies. Table provided by J. A. Knaff, Colorado State University

\begin{tabular}{|lccc|}
\hline $\begin{array}{l}\text { Dvorak } \\
\text { CI } \\
\text { number }\end{array}$ & $\begin{array}{c}\text { Max. sustained } \\
\text { winds } \\
(1,10 \text { min.; knots) }\end{array}$ & \multicolumn{2}{c|}{$\begin{array}{c}\text { Min. central pressure (hPa) } \\
\text { (Dvorak 1975) }\end{array}$} \\
\hline 2.0 & 30,26 & 1003 & 1000 \\
2.5 & 35,31 & 999 & 997 \\
3.0 & 45,40 & 994 & 991 \\
3.5 & 55,48 & 988 & 984 \\
4.0 & 65,57 & 981 & 976 \\
4.5 & 77,68 & 973 & 966 \\
5.0 & 90,79 & 964 & 954 \\
5.5 & 102,90 & 954 & 941 \\
6.0 & 115,101 & 942 & 927 \\
6.5 & 127,112 & 929 & 914 \\
7.0 & 140,123 & 915 & 898 \\
7.5 & 155,136 & 900 & 879 \\
8.0 & 170,150 & 884 & 858 \\
\hline
\end{tabular}

Our finding therefore corroborates recent work noting that upward trends in cyclone strength cannot be identified from the JTWC best track cyclone archive (Kossin et al. 2007) and, similarly, that the most intense cyclones in the South Pacific reveal no increase in maximum wind speed over the last 2 decades (Elsner et al. 2008).

\subsection{Relationships between measured cyclone variables}

The strength of linear relationships between recorded cyclone parameters in the RSMC-Nadi data set was measured using simple Pearson correlation, for which the significance level was then determined using the Student's $t$-statistic. Table 4 illustrates only those relationships that gave correlations (r) stronger than \pm 0.40 . As would reasonably be expected, the length of cyclone tracks in the TSP region (to $25^{\circ} \mathrm{S}$ ) is strongly associated with storm duration $(r=0.83)$, i.e. longer-lived storms produce extended tracks. Similarly, MSLP shows a negative association with cyclone duration ( $r=-0.64$ for 1990-2008), i.e. more intense systems tend to survive longer, although no causality is implied. Other relationships between selected cyclone parameters, such as duration, track length and latitude of origin, all proved highly significant ( $\mathrm{p} \leq 0.001)$, but were generally weak $(|r| \leq 0.57)$.

For the 39 cyclone seasons on record, mean values of all the storms occurring in each season were also calculated. These were then correlated against the seasonal means of the Southern Oscillation Index (SOI) and the Multivariate ENSO Index (MEI), which includes a measure of sea surface temperature (NOAA 2009), averaged over the 6 mo of the TSP cyclone season from November to April. As seen in Table 4, both seasonally averaged SOI and MEI show a strong connection with seasonal means for the latitude of cyclone origin $(|r|=0.69$ and 0.68$)$, but not with cyclogenesis longitude. This means that warm phases of ENSO (El Niño events) are associated with an equatorward (i.e. northward) shift in average cyclogenesis location, whereas cool phases of ENSO (La Niña events) tend to give more southerly cyclone origins. However, eastward or westward shifts in mean cyclogenesis loca-

Table 4. Strongest correlations between selected cyclone parameters. MSLP: minimum sea-level pressure; SOI: Southern Oscillation Index; MEI: Multivariate ENSO Index. ${ }^{* *} \mathrm{p} \leq 0.01 ;{ }^{* * *} \mathrm{p} \leq 0.001$

\begin{tabular}{|c|c|}
\hline Parameters & $\mathrm{r}$ \\
\hline \multicolumn{2}{|l|}{ Individual values $(\mathrm{n}=\mathbf{2 9 1})$} \\
\hline Track length vs. duration & $0.83^{* * *}$ \\
\hline MSLP vs. $\log _{e}$ duration ${ }^{a}$ & $-0.64^{* * *}$ \\
\hline MSLP vs. cyclogenesis latitude ${ }^{\mathrm{a}}$ & $0.46^{* * *}$ \\
\hline MSLP vs. $\log _{\mathrm{e}}$ track length ${ }^{\mathrm{a}}$ & $-0.57^{* * *}$ \\
\hline $\log _{e}$ duration vs. cyclogenesis latitude & $-0.54^{* * *}$ \\
\hline $\log _{\mathrm{e}}$ track length vs. cyclogenesis latitude & $-0.48^{* * *}$ \\
\hline \multicolumn{2}{|c|}{ Seasonal mean values $(n=39)$} \\
\hline Cyclogenesis latitude vs. SOI; MEI & $0.69^{* * *} ;-0.68^{* * *}$ \\
\hline Cyclogenesis longitude vs. SOI; MEI & $-0.41^{* *} ; 0.46^{* *}$ \\
\hline \multicolumn{2}{|l|}{ a1990-1991 to $2007-2008$ data only, $\mathrm{n}=124$} \\
\hline
\end{tabular}


tions are not so clearly linked to seasonal swings in the SOI or MEI. Although Chu (2004) identified a notable increase in storms forming east of $180^{\circ}$ during El Niño phases, our weak correlation between cyclogenesis longitude and seasonal SOI or MEI may partly be explained by the findings of Basher \& Zheng (1995). They noted that for the eastern region of the central South Pacific, i.e. east of longitude $170^{\circ} \mathrm{E}$, favourable atmospheric conditions rather than sea surface temperatures are more important for tropical cyclone development.

\section{CONCLUSIONS}

The present study is among the first to examine the cyclone archive of the RSMC for the TSP, operated by the FMS in Nadi under the designation of the WMO. The data set includes information on tropical storms between 1970 and 2008. Filtering of data to include only the cyclone-intensity phase of the storm events, up to the $25^{\circ} \mathrm{S}$ boundary, shows that 291 tracks formed within or entered the TSP region over the period of record, with a seasonal average of 7 cyclones. From the RSMC-Nadi data the following conclusions emerge:

- Although large variability in the data hinders the assessment of interannual patterns, periods showing notable shifts in cyclone behaviour can nonetheless be identified. Anomalous activity for one or more cyclone parameters occurred in 1976, 1981, 1983, 1991, 1998, 2001-2002 and 2003.

- For individual cyclones, there is a strong or moderate association between storm longevity and both track length and MSLP attained. Other parameters show weak inter-relationships. For seasonally averaged cyclone characteristics, both the SOI and MEI reveal a significant association with cyclogenesis latitude. Otherwise, seasonal strength in SOI or MEI is not a good indicator of other cyclone features.

- No linear trends were revealed in cyclogenesis origins, cyclone duration, track length or track azimuth over 4 decades of records. This implies that there is as yet no evidence for climate-change forcing of these storm characteristics over recent historical times.

- Original unadjusted data for cyclone MSLP appears to suggest a falling trend from 1970 onwards. However, comparison with the Australian BoM and JTWC best track archives reveals strong similarity in MSLP data between these independent data sets and the RSCM-Nadi archive. This implies that the apparent intensity trend is likely to be false, an artefact of the bias introduced by significant changes in methods for determining MSLP over the period of record. No trend in MSLP was detected within the shorter but reliably homogenous part of the RSMC-Nadi record post-1990.
Overall, these findings illustrate that developing South Pacific island nations will remain most vulnerable to episodes of anomalous cyclone behaviour, and that such deviations away from average conditions are likely to continue to be experienced at irregular intervals on an interannual basis. Most importantly, this variability will remain much more of an influence across the TSP region than any small changes linked to long-term trends in cyclone behaviour. Moreover, on a seasonal basis neither the SOI nor MEI are shown to be reliable indicators for assessing these fluctuations and therefore alternative measures need to be developed.

Acknowledgements. The authors would like to acknowledge the help of the Fiji Meteorological Services for providing access to their cyclone data archive. In particular, Mr. S. McGree (Head of Climate Services Division, FMS) and Mr. R. Prasad (Director, FMS) led stimulating discussion on many issues of cyclone-related research. Two anonymous referees provided helpful comments that enabled improvement to the original manuscript. L. K. Lee is thanked for drafting Fig. 2. This research was generously funded by the Taiwan Trade Mission to Fiji.

\section{LITERATURE CITED}

Barnett J, Ellemor H (2007) Niue after Cyclone Heta. Aust J Emergency Manage 22:3-4

Basher RE, Zheng X (1995) Tropical cyclones in the southwest Pacific: spatial patterns and relationships to Southern Oscillation and sea surface temperature. J Clim 8:1249-1260

BoM (Australian Bureau of Meteorology) (2009) Tropical cyclone intensity and impacts. Australian Bureau of Meteorology, Melbourne, available at www.bom.gov.au/ cyclone/about/intensity.shtml

Chu PS (2004) ENSO and tropical cyclone activity. In: Murnane RJ, Liu KB (eds) Hurricanes and typhoons: past, present and future. Columbia University Press, New York, p 297-332

> Dvorak VF (1975) Tropical cyclone intensity analysis and forecasting from satellite imagery. Mon Weather Rev 103: $420-430$

Dvorak VF (1984) Tropical cyclone intensity analysis using satellite data. NOAA Technical Report NESDIS 11, NOAA, Washington, DC

Elsner JB, Lossin JP, Jagger TH (2008) The increasing intensity of the strongest tropical cyclones. Nature 455:92-95

Emanuel K 2004. Response of tropical cyclone activity to climate change: theoretical basis. In: Murnane RJ, Liu KB (eds) Hurricanes and typhoons: past, present and future. Columbia University Press, New York, p 395-407

Emanuel K (2005) Increasing destructiveness of tropical cyclones over the past 30 years. Nature 436:686-688

FMS (Fiji Meteorological Services) (2003) Tropical Cyclone Zoe (04F) (24 December 2002-01 January 2003), preliminary report. Fiji Meteorological Services, Climate Services Division, Nadi Airport

Harper BA, Stroud SA, McCormack M, West S (2008) A review of historical tropical cyclone intensity in northwestern Australia and implications for climate change trend analysis. Aust Meteorol Mag 57:121-141

Klotzbach PJ (2006) Trends in global tropical cyclone activity over the past twenty years (1986-2005). Geophys Res Lett 33:L10805 doi:10.1029/2006GL025881 
Knaff JA, Zehr RM (2007) Reexamination of tropical cyclone pressure-wind relationships. Weather Forecast 22: 71-88

Knutson TR, Tuleya RE (2008) Tropical cyclones and climate change: revisiting recent studies at GFDL. In: Diaz HF, Murnane RJ (eds) Climate extremes and society. Cambridge University Press, Cambridge, p 120-143

Kossin JP, Knapp KR, Vimont DJ, Murnane RJ, Harper BA (2007) A globally consistent reanalysis of hurricane variability and trends. Geophys Res Lett 34:L04815 doi: 10.1029/2006GL028836

Kuleshov Y, Qi L, Fawcett R, Jones D (2008) On tropical cyclone activity in the Southern Hemisphere: trends and the ENSO connection. Geophys Res Lett 35:L14S08 doi:10. 1029/2007GL032983

Landsea CW, Harper BA, Hoarau K, Knaff JA (2006) Can we detect trends in extreme tropical cyclones? Science 313: 452-454

Murnane RJ (2004) The importance of best-track data for understanding the past, present and future of hurricanes and typhoons. In: Murnane RJ, Liu KB (eds) Hurricanes and typhoons: past, present and future. Columbia University Press, New York, p 249-266

NOAA (2009) Multivariate ENSO Index (MEI). NOAA, Silver

Editorial responsibility: Peter Gleckler,

Livermore, California, USA
Spring, MD, available at www.esrl.noaa.gov/psd/people/ klaus.wolter/MEI/mei.html

NOAA (2010) International best track archive for climate stewardship. NOAA Satellite and Information Service and US National Climatic Data Centre, Silver Spring, MD, available at www.ncdc.noaa.gov/oa/ibtracs/index.php?name= data-access

Terry JP (2007) Tropical cyclones: climatology and impacts in the South Pacific. Springer, New York

Terry JP, McGree S, Raj R (2004) The exceptional floods on Vanua Levu Island, Fiji, during Tropical Cyclone Ami in January 2003. J Nat Disaster Sci 26:27-36

Velden C, Harper B, Wells F, Beven JL and others (2006) The Dvorak tropical cyclone intensity estimation technique: a satellite-based method that has endured for over 30 years. Bull Am Meteorol Soc 87:1195-1210

Walsh KJE (2004) Tropical cyclones and climate change: unresolved issues. Clim Res 27:77-83

Walsh KJE, Ryan BF (2000) Tropical cyclone intensity increase near Australia as a result of climate change. J Clim 13:3237-3254

Webster PJ, Holland GJ, Curry JA, Chang HR (2005) Changes in tropical cyclone number, duration, and intensity in a warming environment. Science 309:1844-1846

Submitted: June 29, 2009; Accepted: July 20, 2010

Proofs received from author(s): August 25, 2010 